\title{
Verzeichnis der Handschriften und Abkürzungen
}

$\mathrm{B}=$ Cod. Bodleianus Auct. E 4, 18 (misc. 61), s. X

$\mathrm{B}^{2}, \mathrm{~B}^{3}, \mathrm{~B}^{4}=$ Blätter von zweiter, dritter, vierter Hand in $\mathrm{B}$, s. XII/XIII

$\mathrm{A}=$ Cod. Bodleianus Auct. E II 14 (misc. 42), s. XI

H $=$ Cod. Parisinus 1442, s. XIII

$\mathrm{N}=$ Cod. 211 des Klosters Vatopädi (Athos), s. XIII

$\mathrm{n}=$ Ubereinstimmung von $\mathrm{HN}$

$\mathrm{G}=$ Cod. Angelicus (Rom) 41, s. XII/XIII

$\mathrm{S}=$ Cod. Scorialensis X III 14, s. XII

$P=$ Cod. des Professors Papadopulos-Kerameus (St. Petersburg) und Cod. Parisinus 1248 suppl. gr., s. IX

$\mathrm{P}^{2}=$ zweite Hand in $\mathrm{P}$, s. $\mathrm{X}$

$\mathbf{s}=$ Utbereinstimmung von GS oder GSP

$r=$ Utbereinstimmung von HNGS oder HNGSP

$\mathrm{D}=$ Cod. Parisinus 994, s. XV

$\mathrm{L}=$ Cod. Laurentianus X 18 , s. XI

$\mathrm{y}=$ Ubereinstimmung von $\mathrm{AL}$ (vom dritten Buch $\mathrm{ab}$ )

$\mathrm{F}=$ Cod. Parisinus 1433, s. XI/XII

$\mathrm{V}=$ Cod. Vaticanus 628 , s. XI

$\mathrm{V}^{2}=$ Blätter von zweiter Hand in V, s. XI

$R=$ Cod. Parisinus 1603 A, s. XI

$\mathbf{v}=$ Übereinstimmung von FV oder FVR (bis S. 187)

$\mathrm{z}=$ Ubereinstimmung von DLFV (Buch I) und von $\mathrm{B}^{2}$ (oder $\mathrm{B}^{3}$ ) LFVR (Buch II)

$\mathrm{T}=$ Cod. Marcianus 344, s. XIII; $\mathrm{T}^{*}=$ umgearbeiteter $\mathrm{T}$

$\mathrm{W}=$ Cod. Vindobonensis hist. gr. 8, s. XIV

Für andere Handschriften der indirekten und der Parallelüberlieferung s. S. XI

$\Pi=$ Text der griechischen Handschriften

$\Lambda=$ lateinische Ubersetzung

$\Sigma=$ syrische Utbersetzung

$\mathrm{c}=$ alter Korrektor, $\mathrm{r}=$ junger Korrektor, $\mathrm{m}=$ am Rand. $\mathrm{s}=$ übergeschrieben;

Christ. = Christophorson, Steph. = Robert Estienne, Val. $=$ Valois

Erläuterung der Zeichen

$>=$ läßt aus

$\langle>=$ auf Konjektur beruhender Zusatz

$+=$ fügt hinzu

$\dagger=$ nicht sicher $\mathrm{zu}$ heilende Textverderbnis

$\sim=$ stellt um 